\title{
Exposure to the Chinese Famine in Early Life and the Risk of Metabolic Syndrome in Adulthood
}

\section{Citation}

Li, Yanping, Vincent W. Jaddoe, Lu Qi, Yuna He, Dong Wang, Jianqiang Lai, Jian Zhang, Ping Fu, Xiaoguang Yang, and Frank B. Hu. 2011. Exposure to the Chinese famine in early life and the risk of metabolic syndrome in adulthood. Diabetes Care 34(4): 1014-1018.

\section{Published Version}

doi:10.2337/dc10-2039

\section{Permanent link}

http://nrs.harvard.edu/urn-3:HUL.InstRepos:9807315

\section{Terms of Use}

This article was downloaded from Harvard University's DASH repository, and is made available under the terms and conditions applicable to Other Posted Material, as set forth at http:// nrs.harvard.edu/urn-3:HUL.InstRepos:dash.current.terms-of-use\#LAA

\section{Share Your Story}

The Harvard community has made this article openly available.

Please share how this access benefits you. Submit a story.

Accessibility 


\section{Exposure to the Chinese Famine in Early Life and the Risk of Metabolic Syndrome in Adulthood}

YANPING LI, PHD ${ }^{1,2}$

VINCENT W. JADDOE, PHD ${ }^{2,3}$

LU QI, PHD ${ }^{2,4}$

Yuna HE, MPH ${ }^{1}$

DONG Wang, MSC ${ }^{1}$
JIANQIANG LAI, PHD ${ }^{1}$

JiAN ZHANG, PHD ${ }^{1}$

PING FU, MPH ${ }^{1}$

Xiaoguang Yang, PhD ${ }^{1}$

Frank B. HU, MD, PHD ${ }^{2,4}$

OBJECTIVE_-To examine whether exposure to the Chinese famine during fetal life and early childhood is associated with the risks of metabolic syndrome and whether this association is modified by later life environment.

RESEARCH DESICN AND METHODS_-We used data of 7,874 adults born between 1954 and 1964 from the 2002 China National Nutrition and Health Survey. Famine exposure groups were defined as nonexposed; fetal exposed; and early childhood, midchildhood, or late childhood exposed. Excess death rate was used to determine the severity of the famine. The ATP III criteria were used for the definition of metabolic syndrome (three or more of the following variables: elevated fasting triglyceride levels, lower HDL cholesterol levels, elevated fasting glucose levels, higher waist circumference, high blood pressure).

RESULTS - In severely affected famine areas, adults who were exposed to the famine during fetal life had a higher risk of metabolic syndrome, as compared with nonexposed subjects (odds ratio 3.13 [95\% CI 1.24-7.89, $P=0.016]$ ). Similar associations were observed among adults who were exposed to the famine during early childhood, but not for adults exposed to the famine during mid- or late childhood. Participants who were born in severely affected famine areas and had Western dietary habits in adulthood or were overweight in adulthood had a particularly high risk of metabolic syndrome in later life.

CONCLUSIONS - Exposure to the Chinese famine during fetal life or infancy is associated with an increased risk of metabolic syndrome in adulthood. These associations are stronger among subjects with a Western dietary pattern or who were overweight in adulthood.

Diabetes Care 34:1014-1018, 2011

$\mathbf{F}$ amine studies may give direct evidence for the hypotheses that early malnutrition plays a role in the origins of hypertension (1-3), insulin resistance $(4,5)$, central obesity (6), and dyslipidemia (7), which are all components of the metabolic syndrome. Fetal famine exposure has been shown to be associated with the risk of hypertension in later life in subjects exposed to the

Dutch Hunger Winter (1944-1945) (1), Leningrad Siege (1941-1944) (2), and Chinese famine (1959-1961) (3). Prenatal exposure to both the Dutch Hunger Winter and Chinese famine was also associated with impaired glucose tolerance among adults $(4,5,8)$. Maternal famine exposure during gestation was also associated with higher BMI and waist circumference in Dutch (6) and Chinese women

$\bullet \bullet \bullet \bullet \bullet \bullet \bullet \bullet \bullet \bullet \bullet \bullet \bullet \bullet \bullet \bullet \bullet \bullet \bullet \bullet \bullet \bullet \bullet \bullet \bullet \bullet \bullet \bullet \bullet \bullet \bullet \bullet \bullet \bullet \bullet \bullet \bullet \bullet \bullet \bullet \bullet \bullet \bullet \bullet \bullet \bullet \bullet \bullet \bullet$

From the ${ }^{1}$ National Institute for Nutrition and Food Safety, Chinese Center for Disease Control and Prevention, Beijing, China; the ${ }^{2}$ Department of Nutrition, Harvard School of Public Health, Boston, Massachusetts; the ${ }^{3}$ Departments of Epidemiology and Pediatrics, Erasmus MC, Rotterdam, the Netherlands; and the ${ }^{4}$ Channing Laboratory, Department of Medicine, Brigham and Women's Hospital, and Harvard Medical School, Boston, Massachusetts.

Corresponding authors: Yanping Li, yanping@hsph.harvard.edu; Xiaoguang Yang, xgyangcdc@vip.sina.com; and Frank B.Hu, nhbfh@channing.harvard.edu.

Received 27 October 2010 and accepted 8 January 2011.

DOI: $10.2337 / \mathrm{dc} 10-2039$

This article contains Supplementary Data online at http://care.diabetesjournals.org/lookup/suppl/doi:10 2337/dc10-2039/-/DCl.

(c) 2011 by the American Diabetes Association. Readers may use this article as long as the work is properly cited, the use is educational and not for profit, and the work is not altered. See http://creativecommons.org/ licenses/by-nc-nd/3.0/ for details.

$(9,10)$ and a more atherogenic lipid profile among Dutch adults (7).

The only famine study that examined the associations of fetal famine exposure with metabolic syndrome was conducted in the Dutch Famine Cohort and did not observe significant associations (11). This might be because of the limited period of the Dutch Hunger Winter, which did not last for the whole gestation period, whereas the different metabolic syndrome components have different underlying origins and critical periods (11)

The risks of adverse long-term consequences of famine exposure during early life may be further increased in a nutritionally rich environment in later life $(12,13)$. The associations between low birth weight and later risk of hypertension seem to be stronger among subjects who become overweight in later life $(13,14)$. Our previous study indicated that the association of fetal famine exposure with the risk of hyperglycemia appeared to be exacerbated by Western dietary pattern and improved economic status (8). No previous study had examined the joint association of early life famine exposure and later life nutritional rich environments with the risk of metabolic syndrome during adulthood.

The purpose of present study was to examine whether exposure to Chinese famine during fetal life and childhood was associated with the risk of metabolic syndrome and whether this association was modified by later life nutritional environment.

\section{RESEARCH DESIGN AND METHODS}

\section{Study design and participants}

We used data from the 2002 China National Nutrition and Health Survey (CNNHS), which is a nationally representative cross-sectional study on nutrition and chronic diseases. As has been described in detail previously (8), a stratified, multistage probability cluster sampling design was used in this survey. The final sample size for the analyses was 7,874 . 


\section{Famine cohorts and areas}

Subjects were categorized into five exposure cohorts according to the subject's birthday and corresponding exposure period (8). To minimize misclassification of the famine exposure periods, subjects who were born between 1 October 1958 and 30 September 1959 or between 1 October 1961 and 30 September 1962 were excluded since the exact dates of the start and the end of the Chinese famine were not available and not the same across regions. Adults who were born between 1 October 1962 and 30 September 1964 were classified as nonexposed cohort. Subjects who were born between 1 October 1959 and 30 September 1961 were classified as fetal-exposed cohort whose mother was exposed to famine during the whole gestation period. Subjects who were born between 1 October 1952 and 30 September 1958 were grouped by every 2 years and were classified into one of the three childhoodexposed cohorts.

As previously described, excess death rate of each province was used to determine the severity of the famine $(8,9)$. The excess death rate was calculated as the percent change in mortality rate from the mean level in 1956-1958 to the highest value during the period of 1959-1961. The excess death rate of $100 \%$ was used as the threshold: regions that had equal or higher rate than this cutoff were categorized as severely affected famine areas, and otherwise as less severely affected famine areas. Accordingly, all five birth cohorts were divided into severely affected and less severely affected famine areas.

The protocol of the 2002 CNNHS was approved by the Ethical Committee of the National Institute for Nutrition and Food Safety, Chinese Center for Disease Control and Prevention. Signed consent forms were obtained from all participants.

\section{Study parameters}

Fasting plasma glucose (FPG) concentration was measured using glucose oxidize enzymatic method within $3 \mathrm{~h}$ of plasma preparation (8). Plasma triglyceride and HDL cholesterol were measured enzymatically with a Hitachi 7060, 7180 autoanalyzer (Hitachi, Tokyo, Japan). Subjects' seated blood pressures were measured on the right arm after 5 min of rest to the nearest $2 \mathrm{mmHg}$ according to 1999 World Health Organization/International Society of Hypertension guidelines on hypertension (15). The waist circumference was measured to the nearest $0.1 \mathrm{~cm}$ at the midpoint between the bottom of the rib cage and the top of the iliac crest at the end of exhalation.

\section{Definition of metabolic syndrome}

The ATP III criteria (16) were used for the definition of metabolic syndrome, as three or more of the following variables and cutoff points; 1) fasting triglyceride: $\geq 1.69 \mathrm{mmol} / \mathrm{L}$ (150 mg/dL); 2) HDL cholesterol: men $<1.04 \mathrm{mmol} / \mathrm{L}(40 \mathrm{mg} / \mathrm{dL}$ ), women $<1.29 \mathrm{mmol} / \mathrm{L}(50 \mathrm{mg} / \mathrm{dL}$ ); 3) fasting glucose: $\geq 5.5 \mathrm{mmol} / \mathrm{L}(100 \mathrm{mg} / \mathrm{dL})$ (17); 4) waist circumference: men $>102 \mathrm{~cm}$, women $>88 \mathrm{~cm}$; 5) systolic blood pressure $\geq 130 \mathrm{mmHg}$ and/or diastolic blood pressure $\geq 85 \mathrm{mmHg}$.

\section{Adult nutritional risk factors}

Dietary patterns and BMI measured in 2002 were used as measures of the nutritional environment in adulthood. A validated semiquantitative food frequency questionnaire (FFQ) was used to assess diet in the previous year before the study. The method for assessing dietary patterns has been described in detail elsewhere (18). Briefly, two major dietary patterns, the traditional dietary pattern and Western dietary pattern (8), were derived through cluster analysis of food consumption data collected by the FFQ. We classified subjects as overweight if BMI $\geq 24 \mathrm{~kg} / \mathrm{m}^{2}$, or normal otherwise, using criteria recommended for Chinese adults.

\section{Statistical analysis}

Risks of metabolic syndrome among fetaland childhood famine-exposed subjects, compared with nonexposed subjects, were examined with the method of maximum likelihood by using a survey logistic regression model. Interactions between famine exposure cohort (fetal or childhood exposed vs. nonexposed) and area (severely affected vs. less severely affected) were tested by adding a multiplicative factor in the survey logistic regression model. Analyses were adjusted for sex, economic status, family history of diabetes and hypertension, educational level, current smoking, alcohol use, and physical activity level, all assessed in 2002. To explore whether the associations between fetal exposure to severe famine and metabolic syndrome were modified by improved nutritional environment in later life, we subsequently stratified the analyses by dietary patterns and BMI in adulthood. We conducted two sensitivity analyses: one applying lower cutoff points of waist circumference (men $\geq 90 \mathrm{~cm}$ and women $\geq 80 \mathrm{~cm}$ ) (19) to the definition of the

Table 1-Prevalence and ORs of metabolic syndrome among different birth cohorts stratified by severity of Chinese famine area* $\dagger$

\begin{tabular}{|c|c|c|c|c|c|}
\hline & \multicolumn{5}{|c|}{ Cohort } \\
\hline & Nonexposed & $\begin{array}{c}\text { Fetal } \\
\text { exposed }\end{array}$ & $\begin{array}{c}\text { Early } \\
\text { childhood } \\
\text { exposed }\end{array}$ & $\begin{array}{c}\text { Midchildhood } \\
\text { exposed }\end{array}$ & $\begin{array}{c}\text { Late } \\
\text { childhood } \\
\text { exposed }\end{array}$ \\
\hline \multicolumn{6}{|c|}{ Severely affected famine area } \\
\hline N & 834 & 334 & 641 & 630 & 613 \\
\hline Prevalence (\%) & 3.1 & 7.8 & 7.1 & 5.7 & 6.4 \\
\hline OR & 1.0 (ref) & 3.13 & 2.85 & 2.07 & 2.21 \\
\hline $95 \% \mathrm{CI}$ & & $1.24-7.89$ & $1.19-6.83$ & $0.77-5.53$ & $0.91-5.40$ \\
\hline$P$ & & 0.016 & 0.019 & 0.15 & 0.08 \\
\hline \multicolumn{6}{|c|}{ Less severely affected famine area } \\
\hline$N$ & 1,120 & 671 & 1,013 & 958 & 1,060 \\
\hline Prevalence (\%) & 9.4 & 7.4 & 9.7 & 10.1 & 11.6 \\
\hline OR & 1.0 (ref) & 0.80 & 0.91 & 0.97 & 1.29 \\
\hline $95 \% \mathrm{CI}$ & & $0.46-1.41$ & $0.55-1.51$ & $0.57-1.64$ & $0.76-2.19$ \\
\hline$P$ & & 0.44 & 0.72 & 0.91 & 0.34 \\
\hline $\begin{array}{l}P \text { for interaction be } \\
\text { area and cohort }\end{array}$ & & 0.016 & 0.026 & 0.19 & 0.17 \\
\hline
\end{tabular}

* Metabolic syndrome was defined using criteria of ATP III as at least three of the following: 1) fasting triglycerides $\geq 1.69 \mathrm{mmol} / \mathrm{L}(150 \mathrm{mg} / \mathrm{dL}), 2) \mathrm{HDL}<1.04 \mathrm{mmol} / \mathrm{L}(40 \mathrm{mg} / \mathrm{dL})$ for men and $<1.29 \mathrm{mmol} / \mathrm{L}$ $(50 \mathrm{mg} / \mathrm{dL})$ for women, 3) waist circumference $>102 \mathrm{~cm}$ for men and $>88 \mathrm{~cm}$ for women, 4) fasting glucose $\geq 5.5 \mathrm{mmol} / \mathrm{L}(100 \mathrm{mg} / \mathrm{dL})$, and 5) blood pressure $\geq 130 / \geq 85 \mathrm{mmHg}$. †Prevalence of metabolic syndrome was sex standardized. All ORs use nonexposed cohort as reference cohort (ref). ORs were adjusted for sex, family income, family history of diabetes and hypertension, educational level, current smoking, alcohol use, physical activity level, and BMI. 
metabolic syndrome based on the Asian criterion for abdominal obesity and the other excluding abdominal obesity from the definition of the metabolic syndrome (three or four of: elevated fasting triglyceride levels, lower HDL cholesterol levels, elevated fasting glucose levels, and high blood pressure).

RESULTS - The prevalences of metabolic syndrome among adults in non-, fetal-, and early childhood-, midchildhood-, and late childhood-exposed cohorts were $5.7,7.7,8.4,7.6$, and $8.9 \%$, respectively, in 2002 .

Table 1 shows that in severely affected famine areas, adults who were exposed to the famine during fetal life had a higher risk of metabolic syndrome, as compared with nonexposed subjects (odds ratio
[OR] 3.13 [95\% CI 1.24-7.89, P= $0.016])$. No difference was observed in less severely affected famine areas ( $P$ for interaction between famine cohort and area $=0.016$ ). Similar associations were observed among adults who were exposed to the famine during early childhood. As compared with the nonexposed subjects, the risks of metabolic syndrome among adults who were exposed to the famine during their early childhood were $2.85(95 \% \mathrm{CI} 1.19-6.83, P=$ 0.019 ) and 0.91 (95\% CI $0.55-1.51, P=$ 0.72 ) in severely and less severely affected areas, respectively, with a significant interaction between famine cohort and area $(P$ for interaction $=0.026)($ Table 1$)$.

Results for the analyses stratified by adult dietary patterns and BMI for the associations of early famine exposure with metabolic syndrome are shown in Fig. 1. The fetal famine-exposed cohort with a Western diet in later life had a particularly high prevalence of the metabolic syndrome $(34.6 \%)$, whereas the prevalence among the fetal famine-exposed cohort with a traditional diet in later life was only $4.2 \%$ (Fig. 1A1). No significant difference of metabolic syndrome was found in less severely affected area (Fig. 1B1). Similarly, higher prevalences of metabolic syndrome were observed among overweight adults who were exposed to the Chinese famine during their fetal life (22.6\%) and early childhood (22.5\%) as compared with nonexposed subjects (10.2\%) (Fig. 1A2). Among adults with normal weight, the prevalences of metabolic syndrome were low among adults who were exposed to famine during early

\section{Stratified by later life dietary pattern}

A1

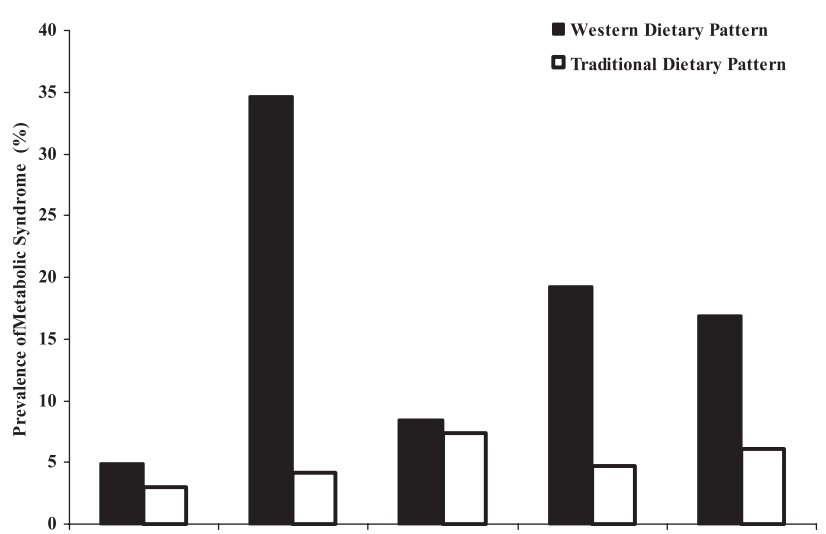

B1

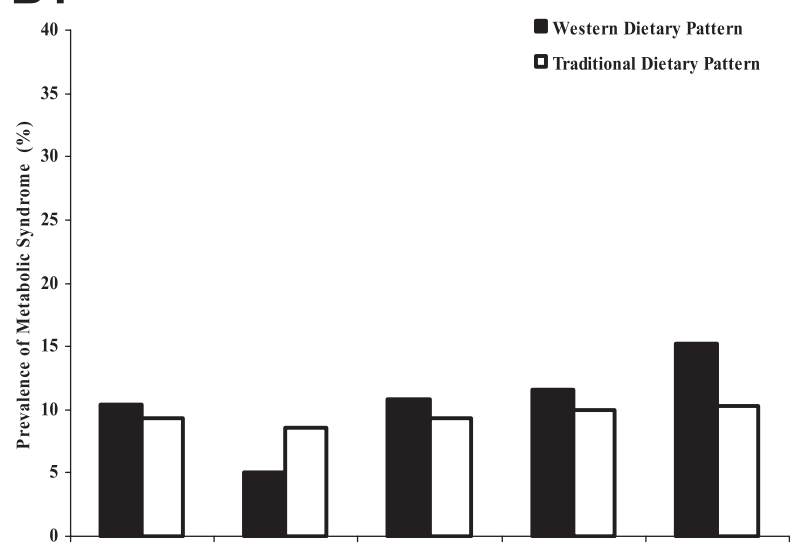

Stratified by later life BMI $\left(\mathrm{kg} / \mathrm{m}^{2}\right)$

A2

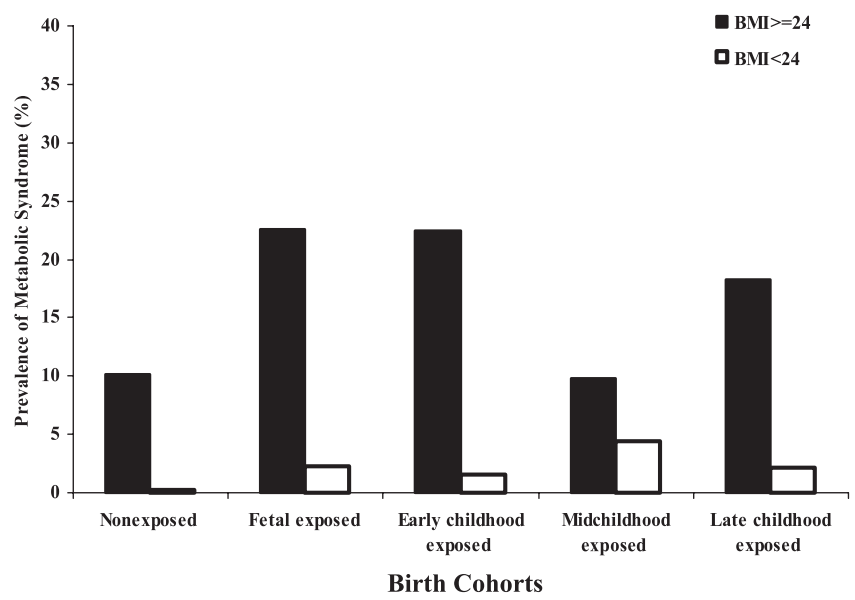

IN SEVERELY AFFECTED AREAS
B2

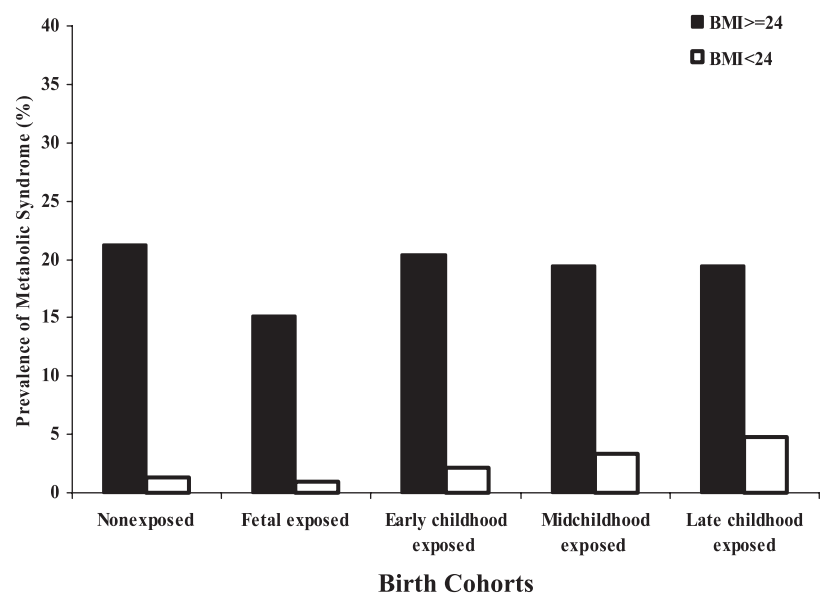

IN LESS SEVERELY AFFECTED AREAS

Figure 1-Prevalence of metabolic syndrome among birth cohorts according to early life famine exposure and later life dietary patterns (1) and BMI (2) in severely (A) and less severely (B) affected famine areas. 
childhood (1.6\%) and fetal period (2.3\%) or were not exposed to famine $(0.2 \%)$ (Fig. 1A2). Overweight adults had significantly higher risk of metabolic syndrome regardless of the severity and age period of the famine exposure (Fig. 1B2). In sensitivity analysis, applying lower cut points for waist circumference (men $\geq 90 \mathrm{~cm}$ and women $\geq 80 \mathrm{~cm}$ ) to the definition of the metabolic syndrome (Supplementary Fig. 1) or excluding abdominal obesity from the definition of the metabolic syndrome (Supplementary Fig. 2) did not materially change the main effect estimates.

CONCLUSIONS - We found that exposure to Chinese famine during fetal life and early childhood was associated with a higher risk of metabolic syndrome in later life. These associations were stronger in subjects who had a Western dietary pattern and subjects who were overweight in adulthood.

Barker et al. (12) and Gluckman and Hanson $(13,20)$ suggested that environmental factors during fetal life and infancy play a role in the origin of the metabolic syndrome and its components. A mismatch between fetal and postnatal environments might exacerbate this effect. To support this hypothesis, the Dutch famine study found that prenatal exposure to famine was associated with higher BMI, higher waist circumference, lower glucose tolerance, higher risk of coronary heart disease, more atherogenic lipid profile, and increased levels of plasma fibrinogen in later life (21). Men who had experienced the siege of Leningrad (1941-1944) during early life had increased mortality from ischemic heart disease and stroke in their adulthood (22). Early life exposure to Chinese famine (1959-1961) was also associated with the increased risk of overweight $(9,10)$, hyperglycemia (8), and hypertension (3) in adult life. The current study provides further evidence that both fetal and infant exposure to severe famine increased the clustering of the metabolic risk factors that predispose a person to type 2 diabetes and cardiovascular disease.

The association between fetal exposure to famine and higher risk of metabolic syndrome was exacerbated by a nutritionally rich environment in later life represented by Western dietary pattern and overweight. This dietary pattern was characterized by high intake of meat, eggs, dairy, sugary beverages, and edible oils and a low intake of vegetables (18).
Our results provide evidence to support the hypothesis that the mismatch between the early life starve environment and later life rich environment magnified the risk of metabolic diseases in later life.

A potential limitation of this study is resident migration across different regions in China, which might lead to misclassification of famine exposure. However, the mobility of the population in rural China is relatively low because relocation of permanent residents needed to be approved by authorities. According to the 2000 China National Population Census, only $2.68 \%$ of the rural population lived in provinces other than their birthplaces (23). Therefore, we do not expect that intraprovince migration led to serious misclassification in famine exposure. Another limitation of our study is the lack of birth weight data, which precludes us from examining the interactions between birth weight and adult overweight or dietary patterns on risk of metabolic syndrome.

Despite these limitations, the current study provided a unique opportunity to test the hypothesis of the joint association between early life famine exposure and later life environment with the risk of metabolic syndrome in adulthood. When compared with other famine studies, the Chinese famine lasted much longer and affected more people.

In conclusion, we found that exposure to severe famine in fetal life and infant period was associated with higher risk of metabolic syndrome in adulthood. A nutritionally rich environment, represented by a Western dietary pattern and overweight, further strengthened the association. Our study indicates that both the early life environment and later life overnutrition are critical for the cardiometabolic health in adult life.

Acknowledgments-The 2002 CNNHS was supported by the Ministry of Health and the Ministry of Science and Technology in China (2001-DEA30035, 2003-DIA6N008), UNICEF, WHO, Unilever China, and Danone Nutrition Institute China. V.W.J. acknowledges personal funding from the Netherlands Organization for Health Research (ZonMw 90700303). Y.L. was also a Takemi fellow in the Department of Global Health and Population at the Harvard School of Public Health.

No potential conflicts of interest relevant to this article were reported.

Y.L. had full access to all data in the study, analyzed data, and contributed to discussion, interpretation of data, and manuscript writing and takes responsibility for the integrity of data and the accuracy of data analysis. V.W.J. and L.Q. contributed to the analysis, interpretation of data, discussion, and the writing of the manuscript. Y.H. had full access to all data in the study, analyzed data, and contributed to discussion, interpretation of data, and manuscript writing. D.W. contributed to the analysis, interpretation of data, discussion, and the writing of the manuscript. J.L., J.Z., P.F., and X.Y. were the principal investigators of the 2002 CNNHS and contributed to discussion, interpretation of data, and manuscript writing. F.B.H. contributed to the study design, discussion, interpretation of data, and manuscript writing and conceptualized and supervised the study.

The authors thank all team members and participants from the 31 provinces in the 2002 CNNHS

\section{References}

1. Stein AD, Zybert PA, van der Pal-de Bruin $\mathrm{K}$, Lumey LH. Exposure to famine during gestation, size at birth, and blood pressure at age $59 \mathrm{y}$ : evidence from the Dutch Famine. Eur J Epidemiol 2006;21: 759-765

2. Stanner SA, Bulmer K, Andrès C, et al. Does malnutrition in utero determine diabetes and coronary heart disease in adulthood? Results from the Leningrad siege study, a cross sectional study. BMJ 1997;315:1342-1348

3. Huang C, Li Z, Wang M, Martorell R. Early life exposure to the 1959-1961 Chinese famine has long-term health consequences. J Nutr 2010;10:1874-1878

4. Ravelli AC, van der Meulen JH, Michels $\mathrm{RP}$, et al. Glucose tolerance in adults after prenatal exposure to famine. Lancet 1998; 351:173-177

5. de Rooij SR, Painter RC, Roseboom TJ, et al. Glucose tolerance at age 58 and the decline of glucose tolerance in comparison with age 50 in people prenatally exposed to the Dutch famine. Diabetologia 2006;49:637-643

6. Ravelli AC, van Der Meulen JH, Osmond C, Barker DJ, Bleker OP. Obesity at the age of $50 \mathrm{y}$ in men and women exposed to famine prenatally. Am J Clin Nutr 1999; 70:811-816

7. Lussana F, Painter RC, Ocke MC, Buller HR, Bossuyt PM, Roseboom TJ. Prenatal exposure to the Dutch famine is associated with a preference for fatty foods and a more atherogenic lipid profile. Am J Clin Nutr 2008;88:1648-1652

8. Li Y, He Y, Qi L, et al. Exposure to the Chinese famine in early life and the risk of hyperglycemia and type 2 diabetes in adulthood. Diabetes 2010;59:2400-2406

9. Luo Z, Mu R, Zhang X. Famine and overweight in China. Rev Agricultural Economics 2006;28:296-304 
10. Yang Z, Zhao W, Zhang X, et al. Impact of famine during pregnancy and infancy on health in adulthood. Obes Rev 2008;9 (Suppl. 1):95-99

11. de Rooij SR, Painter RC, Holleman F, Bossuyt PM, Roseboom TJ. The metabolic syndrome in adults prenatally exposed to the Dutch famine. Am J Clin Nutr 2007; 86:1219-1224

12. Barker DJ, Osmond C, Forsén TJ, Kajantie E, Eriksson JG. Trajectories of growth among children who have coronary events as adults. N Engl J Med 2005;353: 1802-1809

13. Gluckman PD, Hanson MA. Living with the past: evolution, development, and patterns of disease. Science 2004;305: 1733-1736

14. Leon DA, Koupilova I, Lithell HO, et al. Failure to realise growth potential in utero and adult obesity in relation to blood pressure in 50 year old Swedish men. BMJ 1996;312:401-406

15. Guidelines Subcommittee. 1999 World Health Organization-International Society of Hypertension guidelines for the management of hypertension: guidelines subcommittee. J Hypertens 1999;17:151-183

16. Expert Panel on Detection, Evaluation, and Treatment of High Blood Cholesterol in Adults. Executive Summary of The Third Report of The National Cholesterol Education Program (NCEP) Expert Panel on Detection, Evaluation, And Treatment of High Blood Cholesterol In Adults (Adult Treatment Panel III). JAMA 2001; 285:2486-2497

17. Grundy SM, Brewer HB Jr, Cleeman JI, Smith SC Jr, Lenfant C; American Heart Association; National Heart, Lung, and Blood Institute. Definition of metabolic syndrome: Report of the National Heart, Lung, and Blood Institute/American Heart Association conference on scientific issues related to definition. Circulation 2004; 109:433-438

18. He Y, Ma G, Zhai F, et al. Dietary patterns and glucose tolerance abnormalities in Chinese adults. Diabetes Care 2009;32: 1972-1976
19. International Diabetes Federation. The IDF consensus worldwide definition of the metabolic syndrome [article online], 2005. Available from http://www.idf.org/ webdata/docs/MetS_def_update2006. pdf. Accessed 6 December 2010

20. Gluckman PD, Hanson MA. The developmental origins of the metabolic syndrome. Trends Endocrinol Metab 2004;15: 183-187

21. Koupil I, Shestov DB, Sparén P, Plavinskaja $\mathrm{S}$, Parfenova N, Vågerö D. Blood pressure, hypertension and mortality from circulatory disease in men and women who survived the siege of Leningrad. Eur J Epidemiol 2007;22:223-234

22. Song S. Does famine have a long-term effect on cohort mortality? Evidence from the 1959-1961 great leap forward famine in China. J Biosoc Sci 2009;41:469-491

23. State Statistical Bureau. 1949-1989 A Compilation of Historical Statistical Data of Provinces, Autonomous Regions, and Municipalities. Beijing, China Statistical Press, 1990 [in Chinese] 